\title{
MOTION BASED AUTOMATIC STREETLIGHT SYSTEM WITH VEHICLE SPEED SURVEILLANCE
}

\author{
Rezwan us Saleheen \\ Department of Mechatronics Engineering \\ World University of Bangladesh, Dhaka, Bangladesh \\ Saiful Islam \\ Department of Information and Communication \\ Technology \\ Bangladesh University of Professionals (BUP), Dhaka- \\ 1216, Bangladesh
}

\begin{abstract}
Extravagance of electrical energy and human efforts is a common context while using manual switching of streetlights. In most of the cases, the streetlights remain ON during evening, night, even daylight the lights manually are switched OFF. This leads to a lot of energy wastage because lights keep glowing even when there is absolutely no necessity of it. This study aims to develop a smart street light system which glows when the vehicle or pedestrian enters the certain point of the road and make the light be in OFF/Dim position when it is not required. An illustration consisting of a transmitter and a receiver are made to accomplish the goal. The proposed system can turn ON the lights while nightfall and OFF the lights detecting the appearance of daylights. Meanwhile, presence as per the requirement. Hence, the street light will ON only when there are road users are present over there. The system is incorporated with a speed measuring section to reduce rash driving while the road has relatively low traffic density. Compared to the conventional street light system, this streetlight can reduce redundant energy consumption as well as reckless driving tendency.
\end{abstract}

Keywords - Streetlight, Energy, Rash driving.

\section{INTRODUCTION}

Technological infrastructure is the primitive measure of a country's economic growth and welfare. While the technological advancement for improving the quality of life implies with the availability of energy sources [1]. Therefore, the scientists around the world are working round the clock for securing sufficient energy sources. BP statistical review of world energy (2019) illustration shows that, the conventional energy sources produce most of the commercial energies around the globe. But this type of energy source initiates

\author{
Abu Salman Shaikat \\ Department of Mechatronics Engineering \\ World University of Bangladesh, Dhaka, Bangladesh \\ Md. Rezwanur Rahman \\ Department of Mechatronics Engineering \\ World University of Bangladesh, Dhaka, Bangladesh
}

substantial environment impacts like climate change, global warming and environmental pollutions [2]. Hence rises the prospects of renewable energy. However, renewable energy sources are safe in terms of environment issues but structural criterions for such generation may not be reasonable for every territory. Renewable energy structural complications involve the geographical limitations, generation capacity, initial costs, transmission costs etc. [3]. Therefore economizing the applications of energies are a prime concern for the scientists all over the world.

Modern Technology has been also put to work for saving energy. Street lights claim to have a great demand for energy in a country [ $4 \& 5]$. Due to improper management of these street lights every year Bangladesh confronts a considerable energy losses [6]. Such loss of power by street light has significant impact on load management [7]. Hence energy loss due to improper management in the distribution system especially street lights are very alarming. Therefore, the main objective of this work is to design and fabricate an automated control system for street lights to avoid such power loss. However, the automatic streetlight system operates the light management depending on the availability of sunlight. Moreover, the system also fluctuates the intensity of the streetlight which involves economic distribution of energy while any vehicle moving around that light. Furthermore, the system implies a speed measuring section in order to regulate the tendency towards rash driving [8].

Researchers are working round the clock for reducing immoderate applications of energy. Therefore, initiates the tendency towards the uses of automated systems for optimize applications of energies. Several researches were carried out regarding the automation of street light systems. Ankit et al. demonstrates a microcontroller or system on chip (SOC) processor can be used in controlling the lights and fans and also keep the track of how many times the light has been ON 


\section{International Journal of Engineering Applied Sciences and Technology, 2021 \\ Vol. 6, Issue 3, ISSN No. 2455-2143, Pages 1-5 \\ Published Online July 2021 in IJEAST (http://www.ijeast.com)}

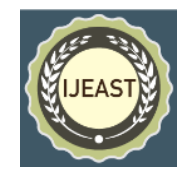

[9]. The system incorporates two distinct mode consisting of wireless sensor networks (WSN), are used for energy conservation such as controlling of lights. Furthermore IoT (Internet of Things) is being implemented on automatic street light system which helps in implementing this street light system in real time and also inform the changes that may occur [10].

Normally automated street light system implies self-initiated switching to reduce human efforts along with proper energy management and controlled through communication networks. Chetna Badgaiyan and Palak Sehgal, illustrated an automatic street light system using PIR sensor and zigbee module. The street light system implies saving power and moving in the direction of development for intelligent streets [11]. The main power source to this street light system is through solar panel, it is adjusted on the top of the pole so that the sunlight directly falls on it. Dr. Mamta Pandey and Shreyansh Pandey demonstrated their research on an energy saving smart solar street light system. Study shows that, most of the countries these days are aware of regular street light system which is not environmental friendly as well as not budget friendly too. The system consists of LED lights operating by solar panels along with DC batteries [12]. However, implementation of such systems can save $80-90 \%$ of the energy approximately.

An energy saving control technology for streetlight system was developed by $\mathrm{Wu}$ Yue, Shi Changhong, Zhang Xianghing and Yang Wei. This street light system works along with the help of multi sensor array (sound, light, infrared, vibration etc) collects information from the environment through which a plan is drawn to control street lights using clock etc [13]. The system detects the movement of people towards the light from long distance $(10 \mathrm{~m})$ then the light to get $\mathrm{ON}$ automatically. When the person is away from the range of $10 \mathrm{~m}$ from the light the light will get OFF automatically. Compared to other control systems, it has good application prospects and easily compatible with photovoltaic LED, fuel cell, solar energy etc.

Vismita Kolvekar et al. instantiated a project on intelligent automatic street light control system. This system is designed in such a way that it does not need any human support to $\mathrm{ON}$ and $\mathrm{OFF}$ the light. This project gives good solution for wastage of electric power in which human involvement is reduced [14]. The entire system includes Raspberry PI acts as brain, which is the main controller which controls whole system. Raspberry PI takes the commands or data from LDR whether it is day or night and from IR sensor whether there is any obstacle present to $\mathrm{ON}$ and OFF the light accordingly. Ashutosh Gupta and Shipra Gupta, designed and implemented an automatic intensity varying street light system [15]. The purpose of designing this type of street light is to develop a street light system without involving any human efforts and works individually while saving energy.
The technology is less costly and easy affair to combine both embedded systems and automation in lighting system including the feature of dimming the light as per the requirements [16]. Mustafa Saad et al. also demonstrates an automatic street light control system using photoelectric sensor for detection [17]. The system purposes to save energy and reduces the human efforts. This whole systems is controlled and operated using microcontroller PIC16f877A. The photoelectric sensor works only during night times. If any obstacles passes from the beam of photoelectric sensor then light will be $\mathrm{ON}$ to which the photoelectric sensor is connected. By using this principle, the street light system is designed efficiently.

Gudinho Diana Minine et al. illustrated a different approach on streetlight automation [18]. Their project emphasizes on an economic and energy efficient streetlight system utilizing piezoelectric materials. Whereas the system used LDR in order to detect the presence or absence of natural lights. Hence produce an automatic switching on streetlights on demand. However, such demonstration considered the piezoelectric effect of materials.

\section{PROPOSED ALGORITHM}

Streetlights has become extremely important regardless to the area concern providing safety and comfort for travelers during nightfall [19]. People tends to prefer automatic systems in any field compared to manual systems in order for efficiency and better living. There are numerous numbers of factors to be considered in order to design the good automatic street light system with the main objectives of public safety, cost-efficient, and energy efficient.

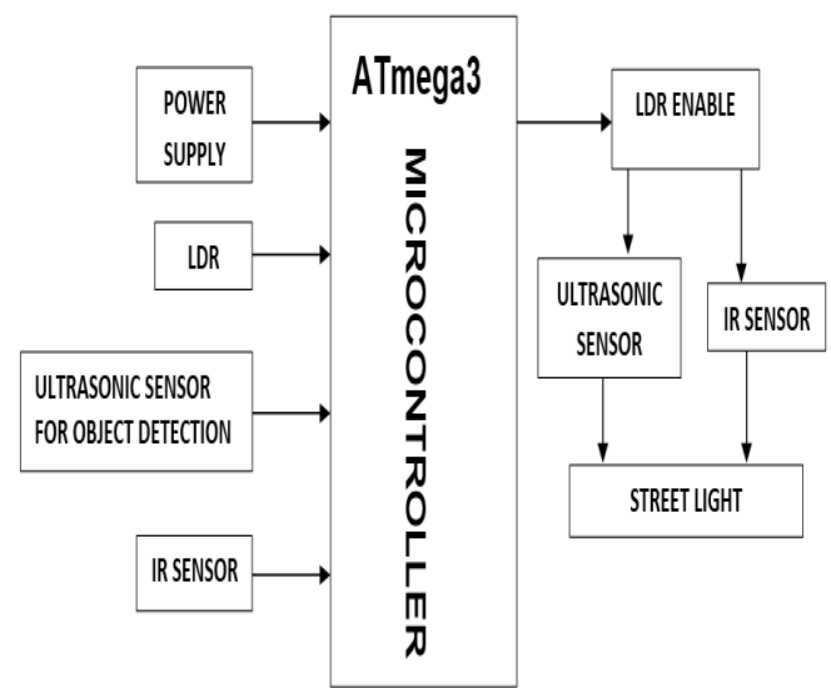

Fig. 1. Block Diagram of the proposed motion-based Streetlight System. 


\section{International Journal of Engineering Applied Sciences and Technology, 2021 \\ Vol. 6, Issue 3, ISSN No. 2455-2143, Pages 1-5 \\ Published Online July 2021 in IJEAST (http://www.ijeast.com)}

The figure (Figure-1) given above illustrates the functional block diagram of the proposed streetlight systems consisting of two distinct parts. They are the transmission end and the receiver end. Ultrasonic sensor is used on the transmitter end and PIR sensors are used on the receiver end to communicate the transmitter and the receiver. The transmitter side sensor detects an obstacle then it sends to receiver with the help of the light will get ON/100\% bright when required whether vehicle may be passing in any speed. Then light will go to OFF/Dim position only when it crosses and moves away from the receiver end. Here the main aim is to ON the light early for the road user so that they does not face any difficulty and put it on OFF/Dim mode when there is no movement through the streets [20].

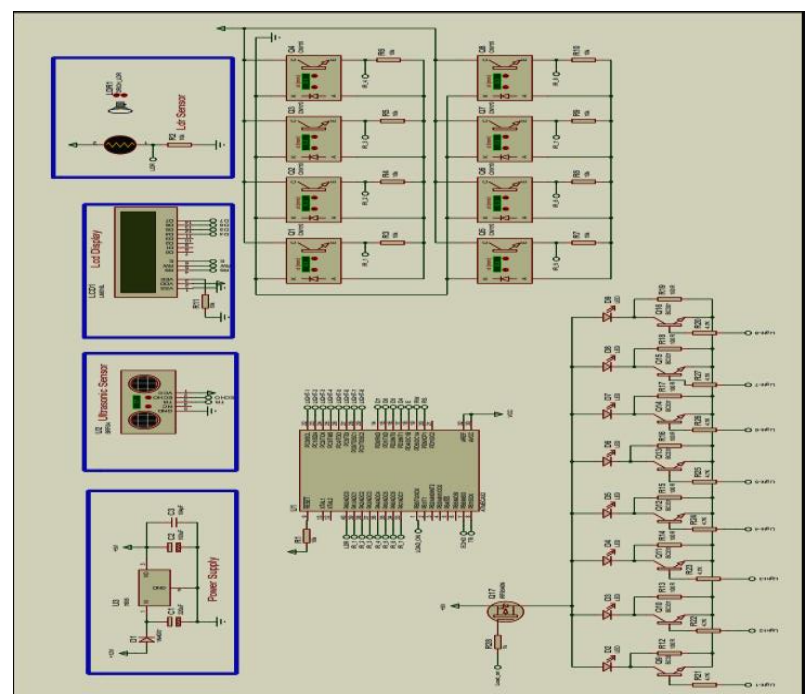

Fig. 2. Circuit Diagram.

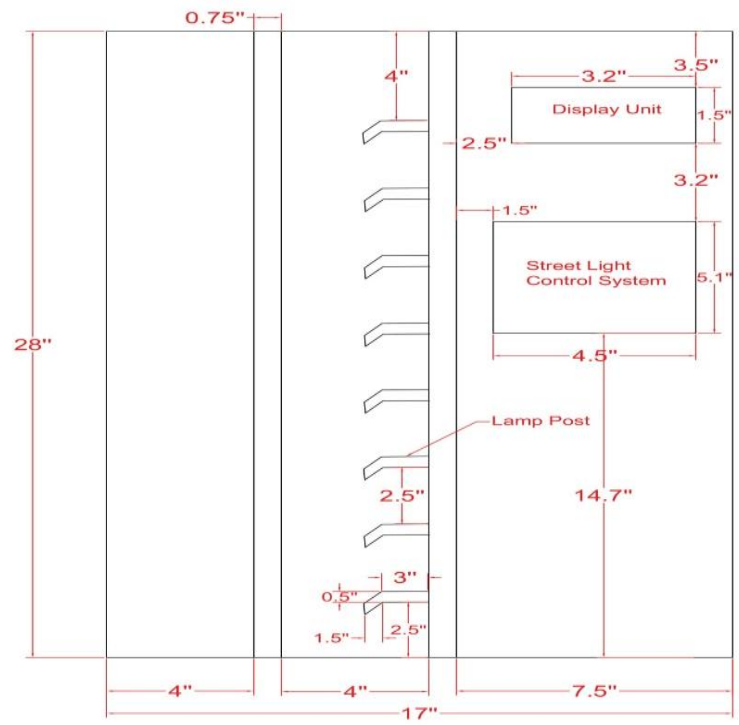

Fig. 3. Mechanical Design.
The proposed smart street light system incorporates transmitter and receiver in such a manner, so that first the transmitter detects the presence of road user and sends data to receiver then light will $\mathrm{ON}$ and incase the transmitter fails to end data then the sensors at receiver end will detect the obstacle and the light will get ON/100\% bright. Then the light will go to OFF position when there are no road users using the road. However, this is a microcontroller based system along with a LDR for the detection of nightfall. Furthermore, the system includes ultrasonic sensor for speed calculation.

\section{EXPERIMENT AND RESULT}

Conventional Streetlight system implies varieties of lights as incandescent light, mercury vapor light, metal halide light, fluorescent light and LED light. The LED light is selected for this design by taken into consideration due to its energy efficiency and good life span. However, LED has about $110^{\circ}$ light emission angle, while conventional lights have $360^{\circ}$ and need a reflector to make the light go the direction which we need. On transmitter end, the ultrasonic sensor is used with Microcontroller for the detection purpose.

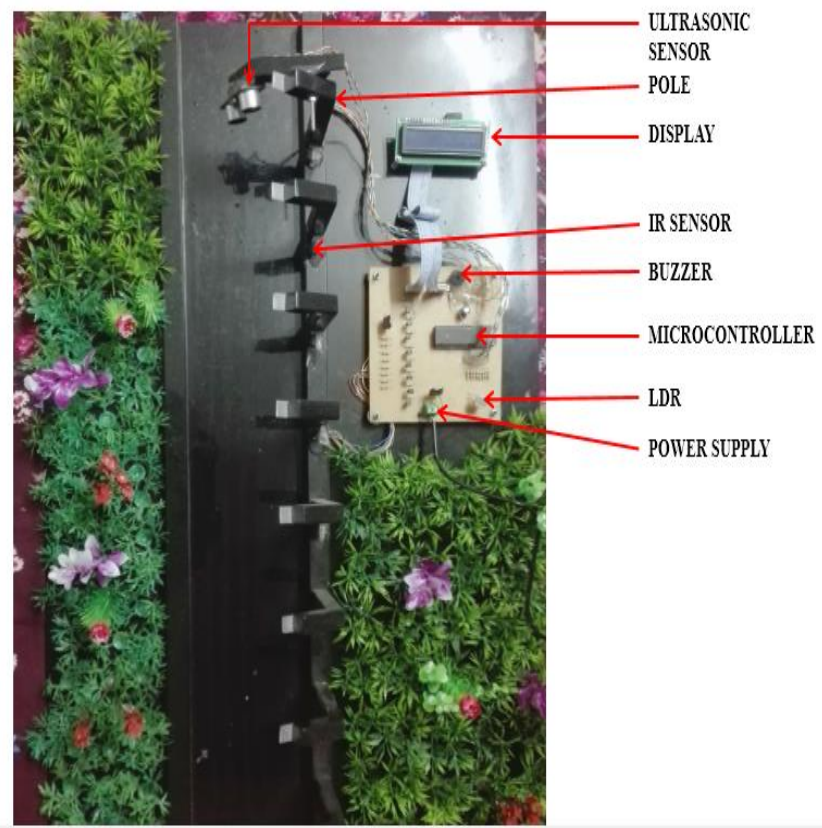

Fig. 4. Project View.

However, the system introduces some time delay for turning on the lights while detects any motion towards that light. Table-1 shows the time at which the vehicle is detected and the time at which the light is ON.

Table -1 Time Required to Turn ON the Lights

\begin{tabular}{|c|c|}
\hline Vehicle speed & Required time \\
\hline $20 \mathrm{KM} / \mathrm{HR}$ & $5 \mathrm{sec}$ \\
\hline $30 \mathrm{KM} / \mathrm{HR}$ & $4 \mathrm{sec}$ \\
\hline
\end{tabular}




\section{International Journal of Engineering Applied Sciences and Technology, 2021 \\ Vol. 6, Issue 3, ISSN No. 2455-2143, Pages 1-5 \\ Published Online July 2021 in IJEAST (http://www.ijeast.com)}

\begin{tabular}{|c|c|}
\hline $40 \mathrm{KM} / \mathrm{HR}$ & $4 \mathrm{sec}$ \\
\hline $50 \mathrm{KM} / \mathrm{HR}$ & $3 \mathrm{sec}$ \\
\hline $60 \mathrm{KM} / \mathrm{HR}$ & $3 \mathrm{sec}$ \\
\hline
\end{tabular}

To reduce the impact of this time delay we have chosen the distance of the sensor such that the system doesn't have any impact of this time delay. In addition, the system reduces the energy consumption [21] up to $57 \%$ comparing with the conventional streetlights having same LED lights. Besides the speed measuring section reduces the tendency towards reckless driving while there is low traffic density. The figure given below demonstrates the prototype of the proposed automatic streetlight system.

\section{CONCLUSION}

Streetlights are a mandatory requirement for moving outside during nightfall. These lights keep the roadway visible along with the safeguard of the people using that streets. However due to the indelicate management of this system, varieties of prodigality and risk arises. The proposed automated streetlight system provides an opportunity to diminish this embezzlement of energy while ensuring precaution against phenomenon like reckless driving. Moreover, such Self- operating system implies less maintenance providing a better living standards. Besides, incorporation of camera and GPS system yield the scope of ensuring a complete surveillance on the streets from a single control Centre. Furthermore, optimization of energy involves the review of design and implementation of energy production and consumption accordingly. Optimal utilization of energy complies conservation by ensuring sufficient energy while provided for everyday use.

\section{REFERENCE}

[1] Uddin M. N., Rashid MM, Mostafa MG, Belayet H, Salam SM and Nithe NA (2016). "Global Energy: Need, Present Status, Future Trend and Key Issues"; Global Journal of Researches in Engineering: (F), Volume-16. Issue-1.

[2] Al-Obaidi A. S. M. and Huynh T Nguyen (2018), "Renewable Vs Conventional Energy: Which Wins the Race to Sustainable Development?", $3^{\text {rd }}$ Annual Applied Science and Engineering Conference (AASEC), Bandung, Indonesia.

[3] Halkos George E. and Gkampoura Eleni-Christina (2020), "Reviewing Usage, Potentials and Limitations of Renewable Energy Sources", Energies 2020, 13(11).

[4] Tamji Mohamad, (2016), "Energy Conservation With Smart Lighting Systems using Microcontroller and IR Sensor", Technical Report IURV.

[5] Devi D. A. and Kumar A. (2012), "Design and Implementation of CPLD based Solar Power Saving
System for Streetlights and Automatic Traffic Controller", International Journal of Scientific and Research Publications, Volume-2, Issue-11.

[6] ADB Technical Assistant Consultant's Report (2013), "Bangladesh: Energy Efficiency Improvement".

[7] Devi D. Asha and Naik L. Prasad (2013), "Prototype Implementation of Power Saver Street Lighting and Automatic Traffic Management System", International Journal of Computer Science and Mobile Computing, Vol. 2, Issue-11.

[8] Singh S., Kumar A., Singh M., Bhatia Prof. S. K. (2018), "Rash Driving Alert Systems", International Journal of Scientific Development and Research (IJSDR), Volume3, Issue-5.

[9] Maleskar A., Aparna K., Mamatha K. and Shivkumar T. (2015), "Smart Lighting System using Rasberry Pi," International Journal of Innovatve Research in Scinece and Technology, Vol.-4, Issue-7, pp 5113-51211.

[10] Priya V. S. and Vijayan M. (2017), “Automatic Street Light Control System using Wsn based on Vehicle Movement and Atmospheric Condition," International Journal of Communication and Computer Technologies, Vol. 5, Issue 2, pp 10-17.

[11] Badgaiyan C. and Sehgal P. (2015), "Smart Street Lighting System"," International Journal of Science and Research, Vol. 4, Issue 7, pp 271-274.

[12] Pandey M. And Pandey S. (2015), "Intelligent Street Lighting System using Automatic Solar led Lamps," International Journal of Science and Technology, vol. 2, issue 4, pp 269-272.

[13] Yue WU, Changhong SHI, Hong Z H and Wei Y. (2010), "Design of new Intelligent Street Light Control System," In control and Automation (ICCA), $8^{\text {th }}$ International Conference on IEEE, Xiamen, china, pp 1423-1427.

[14] Kolvekar V., Vaz V. Shaikh F., Kumari J. and Viegas M. A. (2017), " Intelligent Automatic Street Light Control System," International Journal of Scientific Research and Development, vol. 4, issue 11, pp 202-205.

[15] Gupta A. and Gupta S. (2017), "Design of Automatic Intensity Smart Streetlighting System," IOP Conf. Series: Materials Science and Engineering, Uttar Pradesh, Noida, India, pp 1-5.

[16] Saad M. Farij A. H., Salah A. and Jalil A R A., (2013), "Automatic Street Light Control System using Microcontroller," Mathematical Methods and Optimization Techniques in Engineering, pp 92-96.

[17] Soujanya Ch. N S. (2018), “Automatic Street Light System using Lora Wireless Communication," Asian Institute of Technology, School of Engineering and Technology, Thailand.

[18] Minine G. D., Prabhu P., Bhandary S. Sushmitha, Rao A. P. (2020), "An Energy Efficient Street Light System”, 
Published Online July 2021 in IJEAST (http://www.ijeast.com)

International Research Journal of Engineering and Technology (IRJET), Volume-07, Issue-05.

[19] Choudhury M S H, Munna MMH, Islam N, Islam M R and Islam M A (2018), “ Design and Implementation of an Automated Solar Street Light System," SEU Journal of Science and Engineerin, Vol.- 12, Issue- 1.

[20] Kodali R. and Yerroju S. (2017), "Energy Efficient Smart Street Light", $3^{\text {rd }}$ International Conference on Applied and Theoritical Computing and Communication Technology (iCATccT).

[21] Subramani C., Surya S., Gowtham J., Chari R., Srinivasan S., Siddharth J. P. and Shrimali H. (2019), "Energy Efficiency and Pay-Back Calculation on Street Lighting Systems, AIP Conference Preceedings 2112. 